\title{
Editorial: farewell and thanks
}

\section{Kurt Wüthrich}

(C) Springer Science+Business Media B.V. 2011

Completing my 20th year as the Editor-in-Chief of J. Biomol. NMR, when the Journal reached again an impact factor above 3.0, seemed to be a good point in time to hand the governance of the Journal over to a successor. Our publisher has suggested Prof. Gerhard Wagner of the Harvard University Medical School for the position, and fortunately Dr. Wagner has responded positively to this call. Below you will find Professor Wagner's welcome address with information on his outlook to the future development of J. Biomol. NMR. For me it remains to say 'good-bye' and thank all who have helped to steer and support J. Biomol. NMR during the last two decades, and to wish full success to Gerhard Wagner for a flourishing future development of the Journal of Biomolecular NMR.

Kurt Wüthrich

December 2011 